\title{
Pharmacological Analysis and Molecular Docking of Laurus nobilis (Bay Leaf) for Lung Cancer with Reference to Sirtuin Drug Targets
}

\author{
Seema Rani Padhiary, Kalpana Priyadarsini Das, Meeneri Bobde, Vhatkar Pooja, Sameer Sharma* \\ Department of Bioinformatics, BioNome Private Limited, Bengaluru, India \\ Email address: \\ Sameer21.97@gmail.com (S. Sharma) \\ ${ }^{*}$ Corresponding author \\ To cite this article: \\ Seema Rani Padhiary, Kalpana Priyadarsini Das, Meeneri Bobde, Vhatkar Pooja, Sameer Sharma. Pharmacological Analysis and Molecular \\ Docking of Laurus nobilis (Bay Leaf) for Lung Cancer with Reference to Sirtuin Drug Targets. International Journal of Biomedical Science \\ and Engineering. Vol. 9, No. 2, 2021, pp. 11-15. doi: 10.11648/j.ijbse.20210902.11
}

Received: March 22, 2021; Accepted: April 8, 2021; Published: April 20, 2021

\begin{abstract}
The aim of this in silico study was to analyze the inhibitory activity of selected phytocompounds from the Bayleaf (Laurus nobilis) in contrast to sirtuin proteins using the various pharmacological tools and molecular docking analysis. Laurus nobilis is a perennial herbs native to the family Lauraceae and it has been cultivated throughout the tropical, European, subtropical, and Asian nations. It has been used for thousands of years for food flavoring, essential oil applications, and in traditional medicine. Mostly, it contains all types of secondary metabolites such as tannins, flavones, flavonoids, alkaloids, eugenol, linalool, methyl chavicol, and anthocyanins. The 3D structures of phytocompounds were retrieved from Pubchem and chemspider databases and subjected to various bioinformatic tools such as SwissADME, Modeller, and Autodock for molecular docking to predict the active binding sites of sirtuin proteins. The comparison of molecular docking score exposed that the targeted phytocompounds showed good binding affinity in contrast to anti-cancer sirtuin proteins. The ADME and Molecular docking properties for drug likeness making them significant agents for biological activities and it is expected to be beneficial and effective for cancer. Bayleaf shows an optimistic results towards the treatment of many diseases. The Bayleaf traditionally has healing properties which has now dragged the attention of science for the betterment of humans. The phytochemical compounds found in and taken in the above research have showed good results with cancer receptors Sirtuin1 and Sirtuin4.
\end{abstract}

Keywords: Bayleaf, Flavonoids, Cancer, Molecular Docking

\section{Introduction}

Bay leaf is originated from South Asia as well as it to is related to major and minor Asia and across the globe. Bay leaf (Laur-gus nobilis) is a perennial herb native to the family laurel (Lauraceae). It has been cultivated in European, tropical, subtropical, and Asian countries. Commonly bay leaf used for food flavoring, essential oil applications, food flavoring, and in traditional medicine. It contains most of the flavonoids, tannins, alkaloids, eugenol, linalool, methyl chavicol, and anthocyanins. Bay is commonly using in several industry, from food to cosmetics to pharmaceutical products $[1,2]$.

There are so many variabilities found in bay leaf due to the leaves, stems, morphology, flower color, growth habitat, and chemical composition. Laurus azorica and L. nobilis are the two species of Bay leaf [3]. Bay leaf has a sharp and bitter taste. The main cause of fragnance and Aroma is due to the oil presence in leaves and other part of the plant. The phenolic compounds extracted from bay leaf contains antioxidant properties. different types of bay leaf species contains different types of chemical constituents [4].

Many herbs and spices are there, which are having some limitations for absorbtion as they have full of antioxidants and various differential compounds. But in case of Bay, It's not still exposed that how much bay leaf should be consumed 
to get its health benefits. For the specific amount of use there is no particular recommendations by Researchers. bay is full of antioxidants and is a good source of minerals and dietary fibers $[5,6]$.

To improving the immune system, Bay leaves are the best used herbs which contains various types of Antioxidants such as vitamin $\mathrm{C}$, vitamin $\mathrm{E}$, and carotenoids are used in many dietary sources and are used to lower blood cholesterol and uric acid level [7, 8].

To cure the infections from viruses, bacteria, fungi, and protozoa, bay leaf is very effective. Bay is also helpful in inhibiting growth of carcinogenic cells. Bay is including phytonutrients, catechins, linalool, and parthenolide, which are the unique combination of antioxidants and organic compounds. This combination specifically shown to restrain the proliferation of cervical cancer cells and it helps to protect the body from the effects of free radicals. Free radicals are the main cause of cancerous cells, free radicals mutated healthy cells to carcinogenic cells. And bay leaves are particularly good at preventing this cancerous cells [9].

Bay leaf is found very beneficial in contrast to many infections from fungi, viruses, bacteria, and protozoa. Bay leaves is also helpful in inhibiting growth of cancer causing cells. The unique combination of antioxidants and organic compounds in bay leaves, including phytonutrients linalool, and parthenolide have good results in treatment of cancer [10]. We have selected the flavonoids (Tangeretin, Epicatechn, 8-heptamethoxyflavone, dihydroquercetin, Quercetin, Nobiletin, Isorhamnetin, Naringenin, Kaempferol, Hesperetin, Apigenin, Gallocatechin) from bayleaf to target the particular sirtuin drug targets.

In this paper, we tried a step ahead to do comparative analysis of the selected phytocompounds from the Bay leaf plant with the medicinal phytocompounds and carried out the pharmacological analysis and molecular docking which analyzed the drug likeness of the selected phytocompound.

\section{Materials and Methods}

\subsection{Ligand Preparation}

All the selcted phytocompounds of Bayleaf were retrieved from PubChem databases [11] and Chemspider. And these structures were used for the molecular docking simulation against the sirtuin 1 and 4 protein receptors. All the structures were fetched in the form of Standard Data Format and then converted into Protein Data Bank format using PyMol.

\subsection{Retrieval of Receptors}

Sirtuin 1 and 4 Protein receptors were used as a receptor against selected phytoligands to inhibit the activity of cancer. All the criteria for the receptors were analyzed by BLAST and PDB analysis [12].

\subsection{Homology Modelling for Sirtuin Proteins}

The homology modelling for the sirtuin receptors was done by using SwissModel and Modeller. For SwissModel, the Fasta Sequence were retrieved from NCBI database and subjected into the modelling process. The homology of the selected template for the sirtuin proteins was above $90 \%$ with respect to percent identity.

\subsection{ADMET and Drug-likeness Analysis}

The admet and drug likeness analysis was analyzed through SwissADME and pre admet analysis with the respect to five rule of Lipinski filter analysis. To analyze the orally active drug, there are some standard criteria such as cLogP, molecular mass, hydrogen bond donor and acceptor. All the physiochemical properties of phytocompounds were investigated or filtered by SwissADME, which is known for drug discovery tool [13].

\subsection{Boiled-Egg}

BOILED-Egg is used to predict depend on gastrointestinal absorption and brain barrier for the development of drugs. According to BOILED-Egg plot, if any compounds are rightfully placed in white region of eggs, the probability of GI absorption is higher and brain barrier is higher in case of compound correctly placed in yellow region. In this study, the analysis of the selected compounds for BOILED-Egg was done using SwissADME server [14, 15].

\subsection{Molecular Docking Analysis}

The objective of the molecular docking analysis is to assume or predict the interaction or inhibitory activity of selected phytocompounds in contrast to targeted sirtuin protein receptors. For Molecular docking, the binding affinity or docking score will give you to the all binding pores of molecules insides the catalytic sites of a protein which leads to the proper interaction between the molecules.

For the molecular docking, Autodock Vina, Patchdock, and PyRx (Virtual Docking Tool) were used to check the inhibitory activity of Phytocompounds with leads to the binding affinity and docking score. Once the docking performed, all the hydrophobic interaction was investigated using PyMol version 1.3 [16-18].

\section{Results and Discussion}

\subsection{Ligands}

All the three-dimensional structures of the selected phytocompounds were retrieved from the Pubchem and chemspider databases and leads to the screening through FT Site Server.

\subsection{Analysis of Drug Likeness}

After completion of Lipinski filter analysis which exposed the rigidity of all compound to be remembered for structure-based drug design and also listed out the compound's properties with similar to their usage using ADME analysis. 
Table 1. Physiochemical Analysis.

\begin{tabular}{llllll}
\hline Ligands & $\begin{array}{l}\text { Molecular } \\
\text { formula. }\end{array}$ & $\begin{array}{l}\text { Molecular weight } \\
\text { (g/mol). }\end{array}$ & $\begin{array}{l}\text { Monoisotropic } \\
\text { mass (g/mol). }\end{array}$ & $\begin{array}{l}\text { Heavy atom } \\
\text { count. }\end{array}$ & $\begin{array}{l}\text { Tropological polar } \\
\text { surface area (Angstrom). }\end{array}$ \\
\hline Epicatechin & $\mathrm{C} 15 \mathrm{H} 14 \mathrm{O} 6$ & 290.27 & 290.079038 & 12 & 110.38 \\
Gallocatechin & $\mathrm{C} 15 \mathrm{H} 14 \mathrm{O} 7$ & 306.27 & 306.073953 & 22 & 130.61 \\
Apigenin & $\mathrm{C} 15 \mathrm{H} 10 \mathrm{O} 5$ & 270.24 & 270.052823 & 20 & 90.90 \\
Hesperetin & $\mathrm{C} 16 \mathrm{H} 14 \mathrm{O} 6$ & 302.28 & 302.079038 & 22 & 96.22 \\
Kaempferol & $\mathrm{C} 15 \mathrm{H} 10 \mathrm{O} 6$ & 286.24 & 286.047738 & 21 & 111.13 \\
Naringenin & $\mathrm{C} 15 \mathrm{H} 12 \mathrm{O} 5$ & 272.25 & 272.068473 & 20 & 86.99 \\
Tangeretin & $\mathrm{C} 20 \mathrm{H} 20 \mathrm{O} 7$ & 372.37 & 372.120903 & 27 & 76.36 \\
Isorhamnetin & $\mathrm{C} 16 \mathrm{H} 12 \mathrm{O} 7$ & 316.26 & 316.058303 & 16 & 120.36 \\
Nobiletin & $\mathrm{C} 21 \mathrm{H} 22 \mathrm{O} 8$ & 402.39 & 402.131468 & 16 & 85.59 \\
Quercetin & $\mathrm{C} 15 \mathrm{H} 10 \mathrm{O} 7$ & 302.04 & 302.042653 & 16 & 131.36 \\
dihydroquercetin & $\mathrm{C} 15 \mathrm{H} 12 \mathrm{O} 7$ & 304.25 & 304.058303 & 22 & 127.45 \\
8-heptamethoxyflavone & $\mathrm{C} 22 \mathrm{H} 24 \mathrm{O} 9$ & 432.42 & 432.142032 & 16 & 94.82 \\
\hline
\end{tabular}

Table 2. Lipinski Analysis [13].

\begin{tabular}{llllll}
\hline Ligands & Molecular formula & H-Bond donar & H-Bond acceptor & cLogP & Molar Refractivity \\
\hline Epicatechin & $\mathrm{C} 15 \mathrm{H} 14 \mathrm{O}$ & 5 & 6 & 0.85 & 74.33 \\
Gallocatechin & $\mathrm{C} 15 \mathrm{H} 14 \mathrm{O} 7$ & 6 & 7 & 0.42 & 76.36 \\
Apigenin & $\mathrm{C} 15 \mathrm{H} 10 \mathrm{O} 5$ & 3 & 5 & 2.11 & 73.99 \\
Hesperetin & $\mathrm{C} 16 \mathrm{H} 14 \mathrm{O} 6$ & 3 & 6 & 1.91 & 78.06 \\
Kaempferol & $\mathrm{C} 15 \mathrm{H} 10 \mathrm{O} 6$ & 4 & 6 & 1.58 & 76.01 \\
Naringenin & $\mathrm{C} 27 \mathrm{H} 32 \mathrm{O} 14$ & 8 & 14 & -0.79 & 134.91 \\
Tangeretin & $\mathrm{C} 20 \mathrm{H} 20 \mathrm{O} 7$ & 0 & 7 & 3.02 & 100.38 \\
Isorhamnetin & $\mathrm{C} 16 \mathrm{H} 12 \mathrm{O} 7$ & 4 & 7 & 3.65 & 82.50 \\
Nobiletin & $\mathrm{C} 21 \mathrm{H} 22 \mathrm{O} 8$ & 0 & 8 & 1.23 & 706.87 \\
Quercetin & $\mathrm{C} 15 \mathrm{H} 10 \mathrm{O} 7$ & 5 & 7 & 0.63 & 74.03 \\
dihydroquercetin & $\mathrm{C} 15 \mathrm{H} 12 \mathrm{O} 7$ & 5 & 7 & 3.04 & 113.36 \\
8-heptamethoxyflavone & $\mathrm{C} 22 \mathrm{H} 24 \mathrm{O} 9$ & 0 & 9 & & \\
\hline
\end{tabular}

Criteria $\log \mathrm{P} \leq 5.0$, molecular weight in the range of $150-500, \mathrm{H}$-bond donor's $\leq 5$, and $\mathrm{H}$-bond acceptors $\leq 10$. The result come from the above table indicates that the ligands selected were noted to be in acceptable range defined for human use which shows their potential drug like property.

Table 3. Drug-likeness Analysis.

\begin{tabular}{|c|c|c|c|c|}
\hline Ligands & $\begin{array}{l}\text { Blood brain } \\
\text { barrier }\end{array}$ & GI absorption & $\begin{array}{l}\text { Permeability } \\
\text { glycoprotein substrate }\end{array}$ & $\begin{array}{l}\text { LogS (scale insoluble }<-10<\text { poorly }<-6<\text { moderately }<\text { - } \\
4<\text { soluble }<-2 \text { very }<0<\text { highly) [Water solubility] }\end{array}$ \\
\hline Epicatechin & no & high & yes & -2.22 \\
\hline Gallocatechin & no & high & no & -2.08 \\
\hline Apigenin & no & high & no & -3.94 \\
\hline Hesperetin & no & high & yes & -3.62 \\
\hline Kaempferol & no & high & no & -3.31 \\
\hline Tangeretin & yes & high & no & -4.11 \\
\hline Isorhamnetin & no & high & no & -3.36 \\
\hline Nobiletin & no & high & no & -4.18 \\
\hline Quercetin & no & high & no & -3.16 \\
\hline dihydroquercetin & no & high & no & -2.66 \\
\hline 8-heptamethoxyflavone & no & high & no & -4.38 \\
\hline
\end{tabular}

\subsection{Boiled Egg}

The prediction also reveals that Tangeretin has high GI absorption followed by Nobiletin, 8 heptamethoxyflavone, apigenin known drugs and Naringenin which is then followed by Epicatechin, dihydroquercetin and Gallocatechin have low GI absorption. 

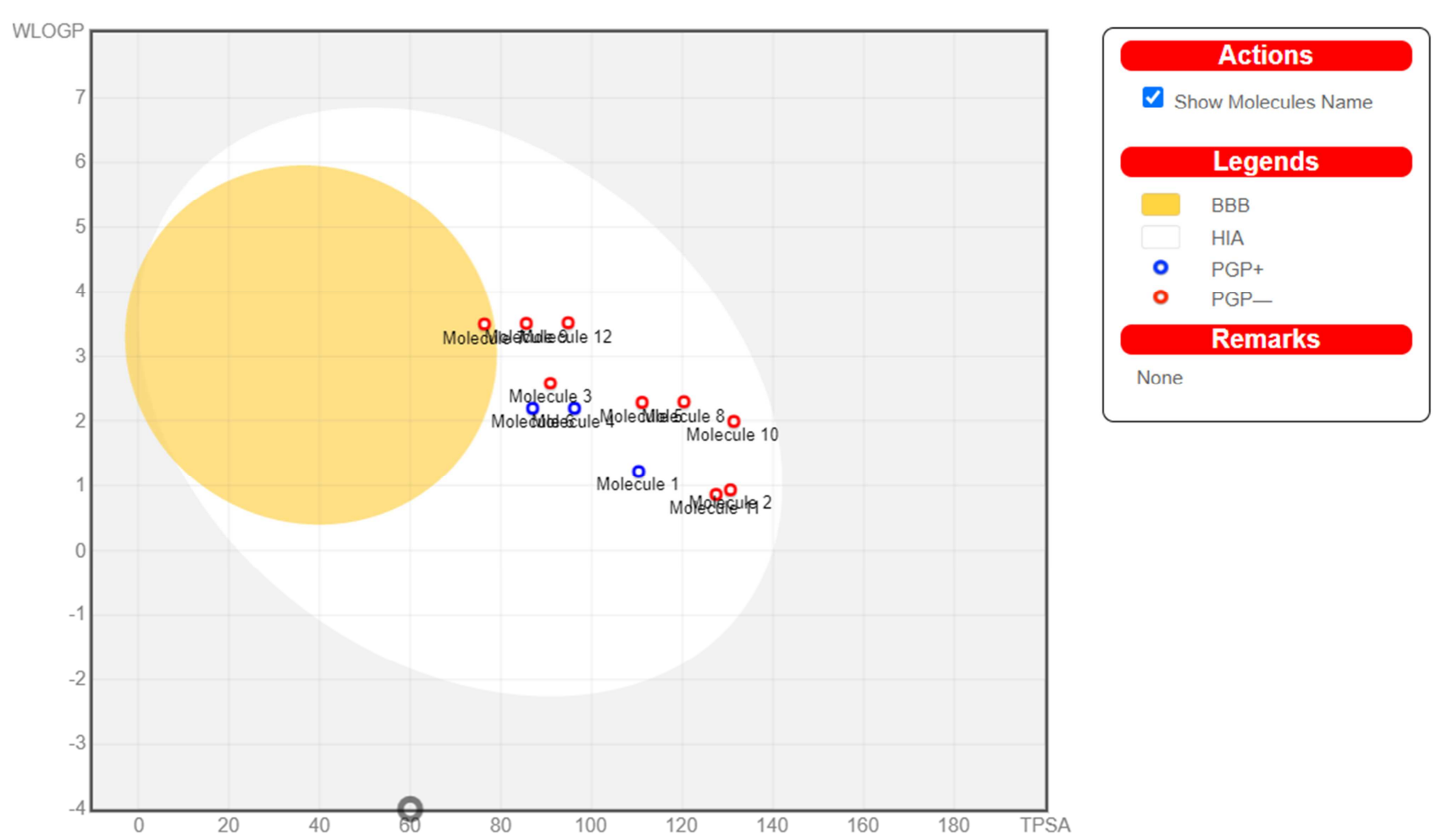

Figure 1. BOILED-EGG Model: The white region indicates the physico-chemical space of molecules with highest probability of being absorbed by the GI (gastrointestinal tract), \& the yellow part indicates the physico-chemical space of molecules with highest probability to permeate to the brain.

\subsection{Molecular Docking Analysis}

The results obtained from molecular docking of selected compounds with Sirtuin1 and Sirtuin4 receptors shows that, most of the compounds are exposing better docking score and binding affinity. And this prediction indicates us to believe that the compounds will be suitable or proper for treatment of Cancer. In selected compounds below, the compounds Epicatechin and 8 Heptamethoxyflavone shows high docking score which indicates good ligands capability. The binding affinity of the compound Naringenin a -8.3 which is having a good binding affinity on comparison to other compounds. This compound is then followed by Isorhamnetin and apigenin with affinity of (-7.6 \&-7.5).

Table 4. Molecular docking simulation with Sirtuin1 co-receptor.

\begin{tabular}{lll}
\hline Ligands & Docking Score & $\begin{array}{l}\text { Binding Affinity } \\
\text { (kcal/mol). }\end{array}$ \\
\hline Epicatechin & 5864 & -7.3 \\
Gallocatechin & 4616 & -7.1 \\
Apigenin & 4220 & -7.5 \\
Hesperetin & 4584 & -7.1 \\
Kaempferol & 4406 & -7.5 \\
Naringenin & 4276 & -8.3 \\
Tangeretin & 4878 & -6.6 \\
Isorhamnetin & 4378 & -7.6 \\
Nobiletin & 4872 & -6.5 \\
Quercetin & 4280 & -6.5 \\
Dihydroquerecetin & 4376 & -7.3 \\
8-Heptamethoxyflavone & 5502 & -6.5 \\
\hline
\end{tabular}

Table 5. Molecular docking simulation with Sirtuin4 co-receptor.

\begin{tabular}{lll}
\hline Ligands & Docking Score & $\begin{array}{l}\text { Binding Affinity } \\
\text { (kcal/mol). }\end{array}$ \\
\hline Epicatechin & 4002 & -3.1 \\
Gallocatechin & 4134 & -6.7 \\
Apigenin & 3886 & -5.4 \\
Hesperetin & 4328 & -6.8 \\
Kaempferol & 3992 & -7.3 \\
Naringenin & 3820 & -6.3 \\
Tangeretin & 4792 & -4.4 \\
Isorhamnetin & 4322 & -3.6 \\
Nobiletin & 5268 & -9.9 \\
Quercetin & 3914 & -11.2 \\
Dihydroquerecetin & 4036 & -5.9 \\
8-Heptamethoxyflavone & 5540 & -8.7 \\
\hline
\end{tabular}

\section{Conclusion}

Bayleaf shows an optimistic results towards the treatment of many diseases. The Bayleaf traditionally has healing properties which has now dragged the attention of science for the betterment of humans. The phytochemical compounds found in and taken in the above research have showed good results with cancer receptors Sirtuin1 and Sirtuin4. The phytochemical compounds Epicatechin and 8 heptamethoxyflavone shows good Docking Score and Binding affinity with Sirtuin receptors 1and 4. The ADME analysis shows that the compound Tangeretin has high absorption rate. Hence, the phytochemical compounds found in Bayleaf extensively paves a wayout to treat lung cancer which has shown good outcome in in-silico studies. 


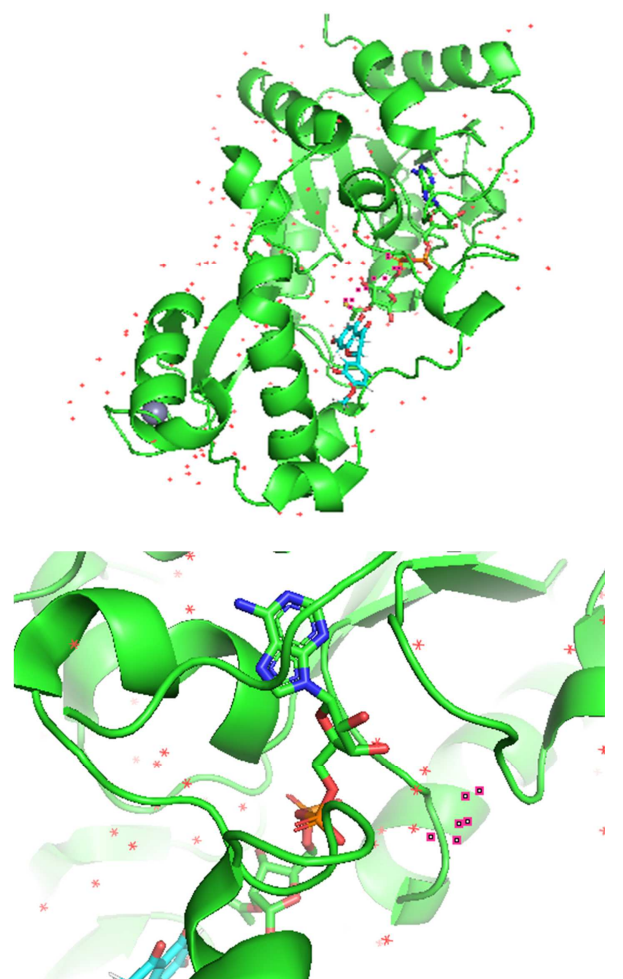

Figure 2. Molecular Docking interaction of selected phytochemical with targeted sirtuin drugs.

\section{Acknowledgements}

We thank BioNome, Bengaluru for helping us to do research in the field of Bioinformatics.

\section{References}

[1] Akgül A., Kivanc M., Bayrak A. Chemical composition and antimicrobial effect of Turkish laurel leaf oil. Journal of Essential Oil Research. 1989; 1: 277-280

[2] Bilen S., Bulut M. Effects of laurel (Laurus nobilis) on the non-specific immune responses of rainbow trout (Oncorhynchus mykiss, Walbaum). Journal of Animal and Veterinary Advances. 2010; 9: 1275-1279.

[3] Bozan B., Karakaplan U. Antioxidants from laurel (Laurus nobilis L.) berries: influence of extraction procedure on yield and antioxidant activity of extracts. Acta Alimentaria. 2007; 36: $321-328$.

[4] Choudhary D., Kala S., Todaria N., Dasgupta S., Kollmair M. Effects of harvesting on productivity of bay leaf tree (Cinnamomum tamala Nees \& Eberm): Case from Udayapur district of Nepal. Journal of Forestry Research. 2014; 25: 163 170 .

[5] Deniz H. Sustainable Collection of Laurel (Laurus Nobilis L.) Leaves in Antalya Province. 2012.

[6] Elmastaş M., Gülçin I., Işildak Ö., Küfrevioğlu Ö., İbaoğlu K., Aboul-Enein H. Radical scavenging activity and antioxidant capacity of bay leaf extracts. Journal of the Iranian Chemical Society. 2006; 3: 258-266.

[7] Erler F., Ulug I., Yalcinkaya B. Repellent activity of five essential oils against Culex pipiens. Fitoterapia. 2006; 77: 491-494.

[8] Fang F., Sang S., Chen K. Y., Gosslau A., Ho C.-T., Rosen R. T. Isolation and identification of cytotoxic compounds from Bay leaf (Laurus nobilis). Food Chemistry. 2005; 93: 497-501.

[9] Aparna Kuna, Somya. M \& Sreedhar. M. Health Benefits of Bay Leaf. MFPI - Quality Control Laboratory, PJTS Agricultural University.

[10] Chaudhry NM, Tariq P. Bactericidal Ăctivity of black pepper, bay leaf, aniseed and coriander against oral isolates. Pak J Pharm Science. 2006; 19: 214-218.

[11] Silveira S, Luciano FB, Fronza N, Cunha Jr A, Scheuermann $\mathrm{GN}$, et al. Laurus nobilis essential oil towards foodborne pathogens and its Application in fresh Tuscan sausage stored at $7^{\circ} \mathrm{C}$. LWT. Food Science and Technology. 2014; 59: 86-93.

[12] Ertürk O. Antibacterial and Antifungal activity of ethanolic extracts from eleven spice plants. Biologia. 2006; 61: 275-278.

[13] Lipinski CA. Lead- and drug-like compounds: the rule-of-five revolution. Drug Discov Today Technol. 2005; 1 (4): 337-341.

[14] Daina A, Michielin O, Zoete V. Swiss ADME: a free web tool to evaluate pharmacokinetics, drug-likeness and medicinal chemistry friendliness of small molecules. Sci Rep. 2017; 7: 42717.

[15] Daina A, Zoete V. A BOILED-Egg to predict gastrointestinal absorption and brain penetration of small molecules. Chem Med Chem. 2016; 11 (11): 1117-1121.

[16] Halgren TA, Murphy RB, Friesner RA, Beard HS, Frye LL, et al. Glide: a new approach for rapid, accurate docking and scoring 2. Enrichment factors in database screening. J Med Chem. 2004; 47 (7): 1750- 1759.

[17] Friesner RA, Banks JL, Murphy RB, Halgren TA, Klicic JJ, et al. Glide: a new approach for rapid, accurate docking and scoring. J Med Chem. 2004; 47 (7): 1739-1749.

[18] Friesner RA, Murphy RB, Repasky MP, Frye LL, Greenwood JR, et al. Extra Precision Glide: Docking and Scoring Incorporating a Model of Hydrophobic Enclosure for Protein-Ligand Complexes. J Med Chem. 2006; 49 (21): 6177-6196. 